\title{
Solusi Metrik Kerr-Newman Untuk Dimensi Ruang-waktu 3+1 Dengan Invariansi Rotasi Anisotropik
}

\author{
Iqbal Lafifa Zulfa ${ }^{1, \dagger}$, Rangga Prasetya Alamsyah ${ }^{2}$, dan Arine Fitriani ${ }^{1}$. \\ ${ }^{1}$ Divisi Fisika Teoretis, Departmen Fisika, Institut Pertanian Bogor. Meranti, Kampus IPB Darmaga, \\ Bogor 16680, Jawa Barat, Indonesia \\ ${ }^{2}$ Program Studi Fisika, Fakultas Sains dan Teknologi, Universitas Islam Negeri Syarif Hidayatullah \\ Jakarta, Jalan. Ir. H. Djuanda No.95, Cempaka Putih, Ciputat, Kota Tangerang Selatan, Banten 15412, \\ Indonesia \\ †Iqbal_Lafzul@apps.ipb.ac.id
}

\begin{abstract}
Abstrak. Metrik Kerr-Newman merupakan solusi umum dari persamaan medan Einstein dengan mengasumsikan metrik ruang waktu melengkung akibat keberadaan objek masif bermassa dan bermuatan, serta memiliki simetri anisotropik akibat rotasi. Metrik Kerr-Newman untuk dimensi ruang-waktu 3+1 diformulasikan pertama kali oleh Ezra Newman. Algoritma umum untuk memformulasikan metrik ini yaitu dengan menggunakan persamaan medan Einstein secara eksplisit, yang meliputi kalkulasi koneksi affine, tensor Ricci hingga tensor energi-momentum. Dimana, formulasi ini tidaklah sederhana. Untuk menyederhanakan formulasi metrik Kerr-Newman untuk dimensi ruang-waktu 3+1, pada artikel ini dilakukan formulasi dengan algoritma alternatif tanpa menggunakan persamaan medan Einstein secara eksplisit. Kemudian, karena algoritma alternatif ini tidak menggunakan persamaan medan Einstein secara eksplisit dan supaya memperoleh solusi metrik Kerr-Newman secara utuh, maka digunakan prinsip limitasi properti metrik Kerr-Newman untuk membawa persamaan medan Einstein secara implisit. Berdasarkan prinsip limitasi properti metrik Kerr-Newman, dilakukan rekayasa matematis atas fungsi temporal serta fungsi radial dari metrik Reissner-Nordstrom dan metrik ruang-waktu datar sistem simetri anisotropik akibat rotasi, yang diturunkan dari transformasi koordinat elipsoid oblate. Dan meski formalisme dengan algoritma alternatif ini relatif sederhana, solusi metrik Kerr-Newman untuk dimensi ruang-waktu $3+1$ pada artikel ini serupa dengan hasil formalisme dan algoritma umum.
\end{abstract}

Kata Kunci: Metrik, Kerr-Newman, Anisotropik, limitasi, Reissner-Nordstrom.

Abstract. The Kerr-Newman metric is a general solution to Einstein field equations by assuming the space-time metric is curved due to the presence of massive objects with mass and a charges, and has anisotropic symmetry due to rotation. The Kerr-Newman metric for the space-time dimension of $3+1$ was first formulated by Ezra Newman. The general algorithm for formulating this metric is to use the Einstein field equation explicitly, which includes the calculation of the affine connection, the Ricci tensor to the energy-momentum tensor. Where, this formulation is not simple. In order to simplify the formulation of the Kerr-Newman metric for the $3+1$ space-time dimension, in this article an alternative algorithm is formulated without using the Einstein field equation explicitly. Then, because this alternative algorithm does not use Einstein field equations explicitly and in order to obtain a complete Kerr-Newman metric solution, the Kerr-Newman metric property limitation principle is used to carry out the Einstein field equation implicitly. Based on the Kerr-Newman metric property boundary principle, do mathematical manipulation on temporal function and the radial function of Reissner-Nordstrom metric and flat spacetime metric system of anisotropic symmetry due to rotation, which is derived from an oblate ellipsoid coordinate transformation. And although the formalism with this alternative algorithm is relatively simple, the Kerr-Newman metric solution for the $3+1$ space-time dimension in this article is similar to the result of formalism from general algorithm.

Keywords: Metric, Kerr-Newman, Anisotropic, The Limitation, Reissner-Nordstrom.

DOI : 10.15408/fiziya.v3i2.18600 


\section{PENDAHULUAN}

Teori relativitas umum dipublikasi oleh Albert Einstein dengan judul "The field equations of gravitation" pada tahun 1915. Teori relativitas umum mendeskripsikan tentang keterkaitan medan gravitasi dengan kelengkungan ruang-waktu, yang divalidasi dengan hasil observasi oleh Eddington pada tahun 1919 [1]. Formalisme fundamental Teori Relativitas Umum dikenal dengan persamaan medan Einstein. Persamaan ini mengonstruksi teori gravitasi dengan ide fundamental yang berbeda dengan ide fundamental teori gravitasi Newton. Berdasarkan teori relativitas umum, entitas gravitasi merupakan manifestasi dari kelengkungan ruang-waktu, yang kelengkungannya ditimbulkan oleh distribusi massa dan energi [2]. Untuk merampungkan teori relativitas umum yang menjelaskan tentang gravitasi sebagai manifestasi dari kelengkungan ruang-waktu, diperlukan persamaan medan gravitasi yang berlaku umum untuk berbagai sistem fisis [2]. Kemudian berdasarkan aksioma matematis aljabar dan kalkulus tensor, lahirlah persamaan medan Einstein. Di mana, kelengkungan ruang-waktu dimodelkan secara matematis sebagai manifold pseudo-Riemannian. Merumuskan solusi umum dari persamaan medan Einstein yang merepresentasikan seluruh properti fisis yang mungkin dimiliki oleh objek sumber gravitasi dalam bentuk fungsi metrik tidaklah mudah. Hal ini karena persamaan medan Einstein adalah persamaan non-linier yang tidak sederhana [2]. Bahkan setelah menuntaskan persamaan medan gravitasinya, Einstein berasumsi tentang tidak mungkinnya memperoleh solusi eksak dari persamaan fundamental teori relativitas umum ini. Namun belum genap setahun persamaan medan Einstein rampung, hal mengejutkan terjadi di tahun 1916. Untuk pertama kalinya, Karl Schwarzschild merumuskan solusi eksak dari persamaan medan Einstein [2-4].

Solusi eksak yang diformulasikan oleh Schwarzchild tidaklah berlaku umum atau tidak merepresentasikan seluruh properti fisis yang mungkin dimiliki oleh objek sumber gravitasi. Solusi ini dibatasi hanya untuk metrik ruang-waktu di sekitar objek masif bermassa yang isotropik dan statis. Artinya variabel tensor Ricci dan tensor energi-momentum akan bernilai nol, sehingga konsekuensi matematis lainnya yakni objek bermassa masif yang dimodelkan oleh Schwarzschild ini berada di ruang hampa. Solusi metrik persamaan medan Einstein merupakan besaran tensorial. Besaran tensor merupakan bentuk perluasan dari besaran vektor dan besaran skalar [2]. Besaran tensor digunakan untuk mengatasi perubahan fungsi metrik atas transformasi koordinat, sehingga solusi metrik persamaan medan Einstein bersifat kovarian atau tidak berubah terhadap transformasi koordinat. Setelah penemuan solusi eksak pertama ini, akhirnya muncul berbagai nama yang merumuskan solusi atas persamaan medan Einstein yang merepresentasikan properti fisis lainnya. Berdasarkan penemuan yang didapatkan oleh Scwarzschild, Roy Kerr merumuskan solusi persamaan medan Einstein yang merepresentasikan properti massa dan rotasi dari objek masif sumber gravitasi [5]. Ide dari Kerr ini pun menjadi fondasi bagi Ezra Newman untuk dapat merumuskan solusi umum atas persamaan medan Einstein pada tahun 1965 [6]. Di mana, Newman merumuskan solusi untuk metrik ruang-waktu di sekitar objek masif bermassa yang anisotropik akibat rotasi, serta bermuatan. Metrik ini familiar dikenal dengan metrik KerrNewman.

Terkait dengan topik artikel ini. Secara teknis menurunkan ulang solusi metrik KerrNewman dalam dimensi ruang-waktu $3+1$ dengan invariansi rotasi anisotropik. Penurunan metrik Kerr-Newman pada artikel ini dilakukan tanpa menggunakan persamaan medan Einstein secara eksplisit. Penggunaan persamaan medan Einstein pada artikel ini secara implisit direpresentasikan oleh metrik Reissner-Nordstrom, sebagai salah satu bentuk limitasi dari metrik Kerr-Newman. Hal ini berdasarkan pada prinsip properti metrik Kerr-Newman, yakni merupakan metrik ruangwaktu di sekitar objek masif bermassa yang anisotropik akibat adanya rotasi, serta bermuatan.

Jika metrik Kerr-Newman diasumsikan sebagai kelengkungan ruang-waktu akibat kehadiran objek lubang hitam, maka lubang hitam dengan simetri anisotropik seperti ini bukanlah hanya sekedar teori matematis, melainkan telah terbukti keberadannya berdasarkan citra visual hasil observasi event horizon telescope [7]. Hal menarik lainnya dari lubang hitam dengan simetri anisotropik adalah dari bentuk singularitasnya. Beda halnya dengan lubang hitam isotropik yang singularitasnya berbentuk titik pada radius nol [8][9]. Singularitas lubang hitam dengan simetri anisotropik ini berbentuk seperti cincin di dalam horizon [2]. Untuk menyederhanakan proses kalkulasi dalam artikel ini, digunakan satuan natural unit dengan ketentuan $G=c=1$. 


\section{LANDASAN TEORI}

\section{Transformasi Koordinat Elipsoid Oblate Dengan Invariansi Rotasi Anisotropik}

Sistem simetri anisotropik dapat diperoleh berdasarkan sistem dengan simetri isotropik, yang direpresentasikan oleh rasio antara vektor basis koordinat kartesian dan vektor basis koordinat polar [2]:

$$
\frac{x_{1}^{2}+x_{2}^{2}+x_{3}^{2}}{r^{2}}=1
$$

Pers.(1) yakni merupakan formulasi dasar transformasi koordinat bola yang invarian terhadap rotasi isotropik. Kemudian, karena metrik Kerr-Newman merepresentasikan kelengkungan ruang-waktu di sekitar objek masif yang berotasi, di mana besaran rotasi berimplikasi kepada nilai radius dimensi $x_{1}$ dan $x_{2}$ yang menjadi relatif lebih besar dibandingkan nilai radius pada dimensi $x_{3}$. Oleh karenanya, maka pers.(1) haruslah dimodifikasi berdasarkan persamaan geometri elipsoid oblate [2]:

$$
\frac{x_{1}^{2}+x_{2}^{2}}{r^{2}+a^{2}}+\frac{x_{3}^{2}}{r^{2}}=1
$$

Pers.(2) merupakan persamaan dasar transformasi koordinat elipsoid oblate yang invarian terhadap rotasi anisotropik. Berdasarkan pers.(2), hasil eksplisit transformasi koordinat dari sistem koordinat kartesian menjadi koordinat elipsoid oblate dapat dituliskan secara matematis:

$$
\begin{aligned}
& x_{1}=\left(r^{2}+a^{2}\right)^{0.5} \sin \theta \cos \phi \\
& x_{2}=\left(r^{2}+a^{2}\right)^{0.5} \sin \theta \sin \phi \\
& x_{3}=r \cos \theta
\end{aligned}
$$

Untuk memperoleh fungsi tensor metrik dari hasil transformasi koordinat pers.(3), dapat diawali dengan mencari fungsi vektor metrik. Fungsi vektor metrik dapat dirumuskan dengan menggunakan metode diferensial terhadap pers.(3). Formulasi diferensial yang merepresentasikan fungsi vektor metrik dapat dituliskan dalam serangkaian bentuk matematis:

$$
\begin{aligned}
d x_{1}= & \frac{r}{\left(r^{2}+a^{2}\right)^{0.5}}+\sin \theta \cos \phi d r+\left(r^{2}+a^{2}\right)^{0.5} \cos \theta \cos \phi d \theta \\
& -\left(r^{2}+a^{2}\right)^{0.5} \sin \theta \sin \phi d \phi \\
d x_{2}= & \frac{r}{\left(r^{2}+a^{2}\right)^{0.5}}+\sin \theta \sin \phi d r+\left(r^{2}+a^{2}\right)^{0.5} \cos \theta \sin \phi d \theta \\
& +\left(r^{2}+a^{2}\right)^{0.5} \sin \theta \cos \phi d \phi \\
d x_{3}= & \cos \theta d r-r \sin \theta d \theta
\end{aligned}
$$

Kemudian berdasarkan aksioma matematis tensor, fungsi tensor metrik merupakan outer product atau hasil perkalian luar dari dua fungsi vektor metrik. Formalisme umum fungsi tensor metrik dapat dituliskan dalam bentuk matematis [2]: 


$$
\begin{aligned}
& d x \otimes d x=\eta_{\mu \nu} d x^{\mu} d x^{v} \\
& d x^{2}=\eta_{\mu \nu} d x^{\mu} d x^{\nu}
\end{aligned}
$$

Dengan tensor metrik kovarian yang dituliskan secara eksplisit [2]:

$$
\eta_{\mu v}=\left(\begin{array}{ccc}
\eta_{11} & \ldots & \eta_{1 n} \\
\vdots & \ddots & \vdots \\
\eta_{m 1} & \cdots & \eta_{m n}
\end{array}\right)
$$

Berdasarkan pers.(7) dan berangkat dari pers.(4),(5),(6), formalisme fungsi tensor metrik dapat dituliskan dalam serangkaian persamaan:

$$
\begin{aligned}
d x_{1}^{2}= & \frac{r^{2}}{r^{2}+a^{2}} \sin ^{2} \theta \cos ^{2} \phi d r^{2}+2 r \sin \theta \cos \theta \cos ^{2} \phi d r d \theta \\
& -2 r \sin ^{2} \theta \sin \phi \cos \phi d r d \phi+\left(r^{2}+a^{2}\right) \cos ^{2} \theta \cos ^{2} \phi d \theta^{2} \\
& -2\left(r^{2}+a^{2}\right) \sin \theta \cos \theta \sin \phi \cos \phi d \theta d \phi \\
& +\left(r^{2}+a^{2}\right) \sin ^{2} \theta \sin ^{2} \theta d \phi^{2} \\
d x_{2}^{2}= & \frac{r^{2}}{r^{2}+a^{2}} \sin ^{2} \theta \sin ^{2} \phi d r^{2}+2 r \sin \theta \cos \theta \sin ^{2} \phi d r d \theta \\
& +2 r \sin ^{2} \theta \sin \phi \cos \phi d r d \phi+\left(r^{2}+a^{2}\right) \cos ^{2} \theta \sin ^{2} \phi d \theta^{2} \\
& +2\left(r^{2}+a^{2}\right) \sin \theta \cos \theta \sin \phi \cos \phi d \theta d \phi \\
& +\left(r^{2}+a^{2}\right) \sin { }^{2} \theta \cos { }^{2} \phi d \phi^{2} \\
d x_{3}^{2} & =\cos ^{2} \theta d r^{2}-2 r \sin \theta \cos \theta d r d \theta+r^{2} \sin ^{2} \theta d \theta^{2}
\end{aligned}
$$

Dengan menjumlahkan masing-masing suku pada setiap vektor basis pada pers.(9),(10),(11), maka dapat diformulasikan fungsi tensor metrik yang lebih sederhana:

$$
\begin{aligned}
d x_{i}^{2}= & \left(\frac{r^{2}+a^{2} \cos ^{2} \theta}{r^{2}+a^{2}}\right) d r^{2}+\left(r^{2}+a^{2} \cos ^{2} \theta\right) d \theta^{2} \\
& +\left[\left(r^{2}+a^{2}\right) \sin ^{2} \theta\right] d \phi^{2}
\end{aligned}
$$

Dengan:

$$
d x_{i}^{2}=d x_{1}^{2}+d x_{2}^{2}+d x_{3}^{2}
$$

Kemudian, berdasarkan metrik Minkowski yang merupakan solusi persamaan medan Einstein untuk ruang-waktu datar ketika tidak adanya objek masif [2]:

$$
\begin{aligned}
& d s^{2}=\eta_{\mu \nu} d x^{\mu} d x^{v} \\
& d s^{2}=d x_{0}^{2}-d x_{1}^{2}-d x_{3}^{2}-d x_{3}^{2} \\
& d s^{2}=d x_{0}^{2}-d x_{i}^{2}
\end{aligned}
$$


Di mana:

$$
d x_{0}^{2}=d t^{2}
$$

Dalam bentuk matriks, pers.(14) dapat diformulasikan:

$$
\eta_{\mu v}=\left(\begin{array}{cccc}
1 & 0 & 0 & 0 \\
0 & -1 & 0 & 0 \\
0 & 0 & -1 & 0 \\
0 & 0 & 0 & -1
\end{array}\right)
$$

Dengan melakukan substitusi pers.(12) terhadap pers.(14) dengan ekuivalensi pers.(15), maka akan didapati formulasi matematis:

$$
\begin{aligned}
d s^{2}= & d t^{2}-\left(\frac{r^{2}+a^{2} \cos ^{2} \theta}{r^{2}+a^{2}}\right) d r^{2}-\left(r^{2}+a^{2} \cos ^{2} \theta\right) d \theta^{2} \\
& -\left[\left(r^{2}+a^{2}\right) \sin ^{2} \theta\right] d \phi^{2}
\end{aligned}
$$

Berdasarkan aksioma matematis geometri ruang-waktu Minkowski [2]:

$$
\eta_{00} \eta_{11}=-1
$$

Maka:

$$
\begin{aligned}
d s^{2}= & \left(\frac{r^{2}+a^{2}}{r^{2}+a^{2} \cos ^{2} \theta}\right) d t^{2}-\left(\frac{r^{2}+a^{2} \cos ^{2} \theta}{r^{2}+a^{2}}\right) d r^{2} \\
& -\left(r^{2}+a^{2} \cos ^{2} \theta\right) d \theta^{2}-\left[\left(r^{2}+a^{2}\right) \sin ^{2} \theta\right] d \phi^{2}
\end{aligned}
$$

Untuk penyederhanaan, pers.(19) dapat dituliskan ulang dalam bentuk formulasi matematis yang ekuivalen:

$$
d s^{2}=A d t^{2}-B d r^{2}-C d \theta^{2}-D d \phi^{2}
$$

Konsekuensi lain dari besaran rotasi yang menyebabkan nilai radius pada dimensi $x_{1}$ dan $x_{2}$ relatif lebih besar dibandingkan nilai radius pada dimensi $x_{3}$, yakni akan muncul suku-suku pada bagian ortogonal untuk dimensi temporal $t$ dan dimensi azimutal $\phi$. Untuk mengeliminasi suku-suku ini dan agar membuat pers.(19) konsisten secara matematis, maka vektor basis dimensi temporal dan dimensi azimutal beserta dengan sukunya haruslah dikoreksi [2]:

$$
\begin{aligned}
& A d T=A(d t \pm p d \phi) \\
& D d \Phi=D(d \phi \pm q d t)
\end{aligned}
$$

Berdasarkan hasil kalkulasi matematis yang telah dilakukan terhadap pers.(19),(20),(21),(22), didapati formulasi matematis sederhana: 


$$
\begin{array}{r}
p=-\left(a \sin ^{2} \theta\right) \\
q=-\left(\frac{a}{r^{2}+a^{2}}\right) \\
D=-\left[\frac{\left(r^{2}+a^{2}\right)^{2} \sin ^{2} \theta}{r^{2}+a^{2} \cos ^{2} \theta}\right]
\end{array}
$$

Sehingga, dapat diformulasikan ulang dengan mempertimbangkan serangkaian hasil koreksi dari pers.(20):

$$
\begin{aligned}
d s^{2}= & \left(\frac{r^{2}+a^{2}}{r^{2}+a^{2} \cos ^{2} \theta}\right)\left[d t-\left(a \sin ^{2} \theta\right) d \phi\right]^{2}-\left(\frac{r^{2}+a^{2} \cos ^{2} \theta}{r^{2}+a^{2}}\right) d r^{2} \\
& -\left(r^{2}+a^{2} \cos ^{2} \theta\right) d \theta^{2}-\left[\frac{\left(r^{2}+a^{2}\right)^{2} \sin ^{2} \theta}{r^{2}+a^{2} \cos ^{2} \theta}\right]\left[d \phi-\left(\frac{a}{r^{2}+a^{2}}\right) d t\right]^{2}
\end{aligned}
$$

Pers.(26) merupakan solusi metrik ruang-waktu datar dari sistem dengan simetri anisotropik akibat adanya rotasi. Namun sistem ini masih berupa abstraksi matematis, karena tidak adanya properti massa yang menjadi faktor esensial terjadinya perubahan dari simetri isotropik menjadi simetri anisotropik. Karena metrik Kerr-Newman memiliki properti fisis rotasi, massa, serta muatan, maka diperlukan 2 properti fisis lainnya untuk melengkapi pers.(26).

\section{Prinsip Limitasi Properti Metrik Kerr-Newman Untuk Dimensi Ruang-waktu 3+1.}

Berdasarkan prinsip properti metrik Kerr-Newman, metrik Kerr-Newman merupakan abstraksi jarak pada ruang-waktu di sekitar objek masif bermassa dengan simetri anisotropik akibat rotasi, serta bermuatan. Dengan mempertimbangkan penyederhanaan seperti pers.(20), maka pers.(26) dapat diformulasikan ulang:

$$
\begin{aligned}
d s^{2}= & A\left[d t-\left(a \sin ^{2} \theta\right) d \phi\right]^{2}-B d r^{2} \\
& -\left(r^{2}+a^{2} \cos ^{2} \theta\right) d \theta^{2}-\left[\frac{\left(r^{2}+a^{2}\right)^{2} \sin ^{2} \theta}{r^{2}+a^{2} \cos ^{2} \theta}\right]\left[d \phi-\left(\frac{a}{r^{2}+a^{2}}\right) d t\right]^{2}
\end{aligned}
$$

Kemudian, fungsi $A$ dan $B$ pada pers.(27) dapat dituliskan dalam bentuk limitasi atas dasar prinsip properti metrik Kerr-Newman:

$$
\begin{aligned}
& \lim _{M, Q \rightarrow 0} A=\frac{r^{2}+a^{2}}{r^{2}+a^{2} \cos ^{2} \theta} \\
& \lim _{M, Q \rightarrow 0} B=\frac{r^{2}+a^{2} \cos ^{2} \theta}{r^{2}+a^{2}}
\end{aligned}
$$

Dan berdasarkan metrik Reissner-Nordstrom Untuk Dimensi Ruang-waktu 3+1 [2][10]: 


$$
\begin{aligned}
d s^{2}= & \left(\frac{r^{2}-2 M r+Q^{2}}{r^{2}}\right) d t^{2}-\left(\frac{r^{2}}{r^{2}-2 M r+Q^{2}}\right) d r^{2} \\
& -\left(r^{2}\right) d \theta^{2}-\left(r^{2} \sin ^{2} \theta\right) d \phi^{2}
\end{aligned}
$$

Dengan mempertimbangkan penyederhanaan yang similar dengan pers.(27), maka fungsi $A$ dan $B$ pada pers.(30) dapat dituliskan dalam bentuk limitasi atas dasar prinsip properti metrik Kerr-Newman:

$$
\begin{aligned}
& \lim _{a \rightarrow 0} A=\frac{r^{2}-2 M r+Q^{2}}{r^{2}} \\
& \lim _{a \rightarrow 0} B=\frac{r^{2}}{r^{2}-2 M r+Q^{2}}
\end{aligned}
$$

Di mana, $M$ dan $Q$ masing-masing merupakan besaran massa serta besaran muatan listrik. Karena pers.(26) merupakan bentuk metrik Kerr-Newman untuk $M=Q=0$, kemudian pers.(30) merupakan bentuk metrik Kerr-Newman untuk $a=0$, maka fungsi $A, B$ metrik Kerr-Newman didapatkan dengan menjumlahkan bentuk limitasi pers.(28) dan pers.(31), serta pers.(29) dan pers.(32):

$$
\begin{aligned}
& A=\frac{r^{2}-2 M r+a^{2}+Q^{2}}{r^{2}+a^{2} \cos ^{2} \theta} \\
& B=\frac{r^{2}+a^{2} \cos ^{2} \theta}{r^{2}-2 M r+a^{2}+Q^{2}}
\end{aligned}
$$

Kemudian, dengan melakukan substitusi pers.(33),(34) terhadap pers.(27), maka didapati formulasi:

$$
\begin{aligned}
d s^{2}= & \left(\frac{r^{2}-2 M r+a^{2}+Q^{2}}{r^{2}+a^{2} \cos ^{2} \theta}\right)\left[d t-\left(a \sin ^{2} \theta\right) d \phi\right]^{2}-\left(\frac{r^{2}+a^{2} \cos ^{2} \theta}{r^{2}-2 M r+a^{2}+Q^{2}}\right) d r^{2} \\
& -\left(r^{2}+a^{2} \cos ^{2} \theta\right) d \theta^{2}-\left[\frac{\left(r^{2}+a^{2}\right)^{2} \sin ^{2} \theta}{r^{2}+a^{2} \cos ^{2} \theta}\right]\left[d \phi-\left(\frac{a}{r^{2}+a^{2}}\right) d t\right]^{2}
\end{aligned}
$$

Untuk penyederhanaan metrik Kerr-Newman untuk dimensi ruang-waktu 3+1, pers.(35) dapat dituliskan ulang dalam bentuk matematis:

$$
\begin{aligned}
d s^{2}= & \left(\frac{\Delta_{K N}}{\rho^{2}}\right)\left[d t-\left(a \sin ^{2} \theta\right) d \phi\right]^{2}-\left(\frac{\Delta_{K N}}{\rho^{2}}\right) d r^{2} \\
& -\left(\rho^{2}\right) d \theta^{2}-\left[\frac{\left(r^{2}+a^{2}\right)^{2} \sin ^{2} \theta}{\rho^{2}}\right]\left[d \phi-\left(\frac{a}{r^{2}+a^{2}}\right) d t\right]^{2}
\end{aligned}
$$

Di mana:

$$
\Delta_{K N}=r^{2}-2 M r+a^{2}+Q^{2}
$$




$$
\rho^{2}=r^{2}+a^{2} \cos ^{2} \theta
$$

Dengan bentuk matematis yang relatif sederhana, pers.(36) merupakan fungsi tensor metrik Kerr-Newman untuk dimensi ruang-waktu 3+1.

\section{HASIL}

Penurunan solusi metrik Kerr-Newman pada artikel ini berdasarkan pada metode matematis transformasi koordinat elipsoid oblate yang invarian terhadap rotasi anisotropik. Selain itu, persamaan medan Einstein tentunya menjadi fondasi fundamental atas lahirnya solusi metrik Kerr-Newman. Berdasarkan hal tersebut, kami merumuskan metode alternatif baru untuk penurunan solusi metrik Kerr-Newman yang diterapkan pada artikel ini. Di mana, penurunan metrik Kerr-Newman dilakukan tanpa menggunakan persamaan medan Einstein secara eksplisit dan menggunakan prinsip limitasi properti metrik Kerr-Newman. Prinsip limitasi properti metrik Kerr-Newman berimplikasi kepada diperolehnya metrik Reissner-Nordstrom yang membawa persamaan medan Einstein secara implisit. Untuk memperoleh solusi metrik Kerr-Newman secara utuh, tahap akhir yang dilakukan ialah rekayasa matematis berdasarkan fungsi temporal serta fungsi radial dari metrik Reissner-Nordstrom dan metrik ruang-waktu datar sistem anisotropik akibat rotasi, yang diturunkan dari transformasi koordinat elipsoid oblate. Hal ini dilakukan untuk memenuhi prinsip properti metrik Kerr-Newman yang memiliki variabel rotasi, massa dan muatan. Karena hasil transformasi koordinat elipsoid oblate yang invarian terhadap rotasi anisotropik hanya menghasilkan properti rotasi, maka secara intuitif dapat ditebak bahwa properti yang didapatkan dari metrik Reissner-Nordstrom yaitu properti massa dan muatan. Meskipun algoritma alternatif baru yang kami rumuskan pada artikel ini relatif sederhana dibandingkan algoritma umum penurunan metrik Kerr-Newman, namun solusi metrik yang diperoleh pada artikel ini tidaklah berbeda dengan solusi metrik yang diturunkan berdasarkan algoritma umum. Solusi metrik Kerr-Newman untuk dimensi ruang-waktu 3+1 pada pers.(36) merupakan pemodelan matematis untuk objek masif di alam semesta yang memiliki properti fisis rotasi, massa dan muatan. Objek masif ini dapat tafsirkan sebagai planet, bintang, bintang katai putih, bintang neutron, ataupun lubang hitam.

\section{KESIMPULAN}

Berdasarkan hasil yang diperoleh dari penelitian ini, dapat disimpulkan bahwa penurunan metrik Kerr-Newman dapat dilakukan secara matematis tanpa menggunakan persamaan medan Einstein secara eksplisit. Di mana, solusi metrik Kerr-Newman yang diperoleh dengan menggunakan persamaan medan Einstein secara eksplisit serupa dengan hasil penurunan metrik Kerr-Newman yang menggunakan prinsip limitasi properti ini.

\section{REFERENSI}

[1] I. L. Saptiani, "Solusi geometri schwarzschild untuk dimensi 4+1 dengan invarian rotasi isotropik," Institut Pertanian Bogor, 2019.

[2] G. P. E. and A. N. L. M. P. Hobson, General relativity: an introduction for physicists. 2006.

[3] K. Kassner, "Dust ball physics and the Schwarzschild metric," Am. J. Phys., 2017, doi: $10.1119 / 1.4982785$.

[4] K. Kassner, "How to obtain the Schwarzschild metric before Einstein's field equations," Adv. Stud. Theor. Phys., vol. 11, pp. 179-212, 2017, doi: 10.12988/astp.2017.61142.

[5] S. O. Alexeyev and V. A. Prokopov, "Shadows from Spinning Black Holes in Extended Gravity," J. Exp. Theor. Phys., 2020, doi: 10.1134/S1063776120040019.

[6] E. T. Newman, E. Couch, K. Chinnapared, A. Exton, A. Prakash, and R. Torrence, "Metric of a rotating, charged mass," J. Math. Phys., vol. 6, no. 6, 1965, doi: 10.1063/1.1704351.

[7] K. Akiyama et al., "First M87 Event Horizon Telescope Results. V. Physical Origin of 
the Asymmetric Ring,” Astrophys. J., 2019, doi: 10.3847/2041-8213/ab0f43.

[8] I. Jihad, D. P. Wardhani, and M. F. Rosyid, "Tinjauan Singularitas Ruang-waktu dalam Teori Relativitas Umum menggunakan Software Maxima,” J. Fis. Indones., 2020, doi: 10.22146/jfi.v22i1.53836.

[9] I. G. N. Yudi Handayana and L. M. Angraini, "SINGULARITAS SEMU PADA RUANG-WAKTU REISSNER-NORDSTRÖM," ORBITA J. Kajian, Inov. dan Apl. Pendidik. Fis., 2019, doi: 10.31764/orbita.v5i2.1203.

[10] J. P. Hong, M. Suzuki, and M. Yamada, "Spherically Symmetric Scalar Hair for Charged Black Holes,” Phys. Rev. Lett., 2020, doi: 10.1103/PHYSREVLETT.125.111104. 